\title{
Effects of Exposure to Bordeaux Mixture on Histological and Ultra Structural Features of Gills of Freshwater Fish Channa Punctatus (Bloch)
}

\author{
Deepasree .M .I, M. S. Rajendran Nair \\ P.G Department of Zoology and Research Centre, Mahatma Gandhi College, Thiruvananthapuram, India
}

\begin{abstract}
Bordeaux mixture acts as an effective fungicide because of the copper ions $\left(\mathrm{Cu}^{2+}\right)$ of the mixture. Sub lethal concentration of Bordeaux mixture was investigated with fresh water teleost fish Channa punctatus. The present study deals with the deleterious effects of copper ions present in 13.06ppm Bordeaux mixture at the ultra structural levels of the gills of Channa punctatus $\left(1 / 10^{\text {th }}\right.$ of LC 5096 hrs).The gill histology was studied under light and scanning electron microscopy. Bordeaux mixture is having the capacity to make deleterious pathological changes in gills of fishes. The major changes observed were a distortion in the shape of secondary lamellae, epithelial hyperplasia, lamellar fusion, epithelial lifting, and epithelial necrosis of secondary lamellae. Fusion of secondary lamellae, shrinked or curved lamellae and vacuolization at the tip of the primary gill lamellae were the observed as characteristic feature of the pesticide exposed fish. The severity of the lesions was found to be increased with increase in exposure period.
\end{abstract}

Keywords: Channa punctatus, Bordeaux mixture, epithelial hyperplasia, epithelial lifting, epithelial necrosis.

\section{Introduction}

The application of pesticides has become an essential part of present day agricultural practices. The benefits due to the use of pesticides are numerous but at the same time they cause considerable harm to the ecosystem. Pesticide usage is a critical concern which may have an adverse effect on the delicate ecosystem. In many areas of the world, these sensitive ecosystems are at a risk because of a non point source runoff of pesticides from agricultural and urban sources to aquatic ecosystems affecting aquatic biota (Austin; 1999; Srivastava etal; 2008). Pesticides not only alter the physico chemical properties of water but also adversely affect the aquatic organisms (De Vlaming etal; 2000; Parma etal; 2007). These chemicals also pose human concern because they are toxic substances released either directly or indirectly to aquatic environment. Most of the pesticides have undergone some toxicity testing to evaluate its effect on non target organisms. Unfortunately these pesticides at high concentration are known to reduce the survival, growth and reproduction of fishes. Incorporation of these toxic chemicals, even at low concentration in the vital tissues of fishes and birds has been reported to cause serious morphological alterations (Chakraburthy and Konar; 1974; Mathur etal; 1981, Vijayalekshmi and Tilak 1996).

Bordeaux mixture acts as an effective fungicide because of the copper ions $\left(\mathrm{Cu}^{2+}\right)$ of the mixture. These ions react with enzymes in the fungal spores in such a way as to prevent spore germination. The Bordeaux mixture can also be used as a precaution, before the onset of fungal attack (Pears Pauline, et al., 2005). Bordeaux mixture has been found to be harmful to target fungi, as well as non target organisms like fish and livestock .Chemical Formula: $\mathrm{Ca}_{3} \mathrm{Cu}_{4} \mathrm{H}_{6} \mathrm{O}_{22} \mathrm{~S}_{4} \mathrm{H}_{2} \mathrm{O}$.

Channa punctatus has greater economic importance because it is an edible fish. The flesh is good and tasty, so it is having good commercial value. Channa punctatus can be abundantly seen in paddy fields and marshy areas but its occurrence is very less in river or running water. Water pollution, in Kerala mainly agricultural and industrial pollution is potential threats to the species.

Gill is the main osmoregulating organ in fishes, and it is highly sensitive to many factors, including stress, pollution and changes in the salinity of environment.

\section{Materials and Methods}

Adult specimen of healthy Channa punctatus of both the sexes, measuring average length $14.18 \pm 1.03 \mathrm{~cm}$, weight $41.6 \pm 7.9 \mathrm{gm}$ were collected using cast net from a pond at Neduvathoor, Kottarakara, Kerala. The collected fishes were transported to the laboratory in aerated containers. Fishes were treated with $2 \% \mathrm{KMnO} 4$ solution for 15 minutes to remove external contamination and kept in tanks having capacity of 25 litres filled with 20 litres of well water, and acclimatized for 15 days with continuous aeration and fed with dry shrimps and pieces of earthworms; the water was renewed in every $24 \mathrm{hrs}$.

Ten fishes were taken both in control and treated tanks. The physicochemical parameters of water in which the fishes were kept were analyzed prior to setting up of the experiment and during the course of experiment.

In the present study, short term static toxicity test was done using Channa punctatus and the mortalities were observed after exposure to different concentration of Bordeaux Mixture under laboratory conditions. Neither the control nor the experimental fish were fed during the experiment.

To study the sub lethal effect of Bordeaux mixture on tissue anatomy (short term), an experiment was conducted in which the experimental fishes were divided in to two groups. In first group fish were exposed to $13.06 \mathrm{ppm}$ of Bordeaux mixture for $24 \mathrm{hr}, 48 \mathrm{hr}, 72 \mathrm{hr}$ and $96 \mathrm{hrs}$ and in 


\section{International Journal of Science and Research (IJSR) \\ ISSN (Online): 2319-7064}

Index Copernicus Value (2013): 6.14 | Impact Factor (2014): 5.611

the second group a control set of fish was running. The LC50 of Bordeaux mixture for $96 \mathrm{hrs}$ was calculated as $13.06 \mathrm{ppm}$ through the probit analysis. During the experimental period dead fish were removed immediately and the water was changed regularly at $24 \mathrm{hr}$ intervals with the same amount of the toxicant. At the end of specified period of experimental exposure, gill tissues were dissected out for histological process after sacrificing the fish.

The gills were dissected out, pooled and fixed in Bouin's fixative. The fixed tissues were cleared in chloroform .The tissues were dehydrated and embedded in paraffin wax at $60^{\circ} \mathrm{c}$.Sections cut at $5 \mu \mathrm{m}$ thickness were stained with Haematoxylin \&Eosin $(\mathrm{H} \& \mathrm{E})$ and photomicrographs were taken.

To elucidate the ultra structural morphological deleterious changes on the epithelial surface of the gills of Channa punctatus, upon exposure to lethal concentration of Bordeaux mixture (13.06ppm), for $96 \mathrm{hrs}$, the gill filament was subjected to Scanning Electron Microscopic (SEM) investigations. SEM-study confirmed the results obtained by light microscopy.

\section{Results}

In the present study on exposure to Bordeaux mixture, the gill of Channa punctatus showed severe histopathological changes. As fish gills are the critical organs for their respiratory and osmoregulatory functions, the injuries in gill tissues were observed to reduce the oxygen consumption and disrupt the osmoregulatory functions of the fish.

In Channa punctatus, there are four pairs of semicircular gill arches. Each gill arch of control fish has two rows of microscopic primary gill lamellae on which secondary gill lamellae are arranged bilaterally. The gill lamellae are so delicate and have blood sinusoids which are necessary for effective gas exchange during respiration (Fig.1, Fig.5).

Bordeaux mixture is having the capacity to make deleterious pathological changes in gills of fishes. The major changes observed were a distortion in the shape of secondary lamellae, the gill lamellae were cut into pieces, necrosis occurred and vacuoles also developed in the gill epithelium and the rupture of epithelial cells in the secondary gill lamellae (Fig.2).

Epithelial hyperplasia, lamellar fusion, epithelial lifting, epithelial necrosis of secondary lamellae were also observed. The gills were swollen in comparison to the gills of control fish because of the hypertrophy and hyperplasia of the gill epithelial cells. Fusion of secondary lamellae and oedema, were observed (Fig.6, Fig.7).

Clubbing of the ends of the lamellae, a tendency of fusion of adjacent lamellae and Vacuolization at the tip of the primary gill lamellae is a characteristic feature of the Bordeaux mixture exposed fish. The epithelial cells of gill filament have shrunken resulting in the lifting of epithelial cells (Fig.3).
SEM-study confirmed the results obtained by light microscopy. At low resolution, a normal arrangement of gill filaments and lamellae was observed. Spiking of lamellae, gradual fusion of lamella and transformation of filaments into club like structures were some of the noticeable changes induced by Bordeaux mixture exposure. There were unambiguous quantitative and qualitative changes in the surface morphology of gills of the pesticide exposed fish. A gradual smoothing of the superficial pattern and dilation of microridges were also observed at few places in pesticide exposed groups of fishes.

\section{Discussion}

Histopathological changes have been used as important biomarkers in environmental monitoring that allows examining specific target organs. The histological results observed in all the tissues of Channa punctatus in the present study indicate that sub lethal concentrations caused moderate to severe alteration in gill architecture, which are important organs performing vital function like respiration and osmoregulation.

During the present investigation the Channa punctatus, were exposed to pesticide, Bordeaux mixture, the gills showed an intense mucus secretion throughout the exposure period. The intense secretion of mucus may be due to mucins, (poly anions) composed of glycoprotein that can be effective in trapping toxicants and aid in the prevention of toxicant entry into the gill epithelium (Khangarot and Tripathi, 1991, Perry, S.E. and Laurent, P. 1993).

The gills showed deterioration in the epithelial lining and degeneration of the rachis, swelling of primary and secondary gill lamellae indicating hyperplasia. Gill hyperplasia might serve as a defensive mechanism leading to a decrease in the respiratory surface and an increase in the toxicant-blood diffusion distance (Morgan and Tovellt 1973). This may be due to the presence of Copper ions in Bordeaux mixture. Similar observation was done by Agnihotri et al., 2010 in their studies on gill lamellae of fresh water fish Channa punctatus due to Arsenic ions. Epithelium lifting was observed in the Bordeaux mixture treated gills. Epithelial lifting increases the distance between blood and epithelial layer and thus decrease velocity of penetration of the molecules of Bordeaux mixture in to blood. So the epithelial lifting can be considered as a defence mechanism adopted by fishes to slow down the penetration of pesticide through lamellar epithelium. The epithelial lifting in gills decelerate oxygen uptake and produce dysfunctional gills, and eventually asphyxiate the fish (Kumar et al., 2010).

Clubbing of the ends of the gill lamellae and a tendency of fusion of adjacent lamellae were the general effects observed on gills due to Bordeaux mixture exposure. The lamellar fusion could be a protective mechanism as it helps in reducing the surface area of gills, so that the gill surface area exposed to pesticide also reduces (Ortiz, J., 2003). 


\section{International Journal of Science and Research (IJSR) \\ ISSN (Online): 2319-7064 \\ Index Copernicus Value (2013): 6.14 | Impact Factor (2014): 5.611}

Gill lesions associated with the lamellar aneurysm were observed in prevalence in all treatment groups. The lesions may be due to the disturbance of blood flow in the blood channels. Similar histopathological lesions have been reported by Campagna, A., (2007) in Danio rerio juveniles, in chlorpyrifos exposed Channa punctatus (Yogitha Devi and Abha Mishra 2013) and in Channa punctatus due to Glyphosate based herbicide exposure (Senapati etal. 2009)

\section{Conclusion}

Large scale application of pesticides, insecticides and other chemicals has drastically deteriorated the quality of aquatic ecosystems. The present investigation revealed that the degenerative changes due to the exposure of Bordeaux mixture were comparatively more pronounced in the gills of Channa punctatus. This may due the fact that gills may remain in direct contact with the pesticide polluted surrounding water. The acute exposure of $\mathrm{cu}^{2+}$ ions in the selected pesticide Bordeaux mixture may cause serious physiological problems ultimately leading to the complete mortality of fish. To conclude, it is strongly recommended that, every farmer should have an appropriate knowledge about the responsible use of pesticides.

\section{Acknowledgement}

I am extremely grateful to the Department of Zoology, M.G College, Trivandrum .I also express my sincere gratitude to the Electron Microscopy Division of SreeChithira Trirunal Institute of Medical Science and Technology (SCTIMST), Trivandrum.

\section{References}

[1] Agnihotri U.S., R.B.Bahadure and S.R.Akarte (2010): Gill lamellar changes in fresh water fish Channa punctatus due to influence of Arsenic trioxide.Biosci.Biotech. Res.Comm.Vol. (3) No. (1) June, 2010(61-65).

[2] Austin, B.1999. The effects of pollution on fish health.j.Appl.Microbiol. 85, 234-242.

[3] Campagna, A., Eler, M., Fracacio, R., Rodrigues, B. and Verani N., (2007). The toxic potential of aldrin and heptachlor on Danio rerio juveniles (Cypriniformes, Cyprinidae). Ecotoxicol. 16: 289298.

[4] Chakraburthy, Gouri and S.K. Konar .1974: chronic effects of sub lethal levels of pesticides in fish.Proc.Nat.Acad.Sci.India, 44B, 241-246.

[5] De Vlaming, V., V.Connor, C.DeGiorgio, H.C.Bailey, L.A.Deanovic and D.E.Hinton. 2000: Application of whole effluent toxicity test produces to ambient water quality assessment .Environ.Toxicol.Chem. 19, 42-62.

[6] Khangarot, B.S and Tripathi, D.M., 1991 changes in humoral and cell mediated immune response in skin and respiratory surfaces of cat fish, Sacchobranchus fossilis following copper exposure.Ecotoxicol.Environ.Saf.22:291-308).

[7] Kumar, M., Prasad, M. R., Srivastva, K., Tripathi, S., and Srivastva, A. K., (2010) "Branchial histopathological study of Catfish Heteropneustes fossilis following exposure to purified neem extract, Azadirachtin." World Journal of Zoology, 5(4), pp.239-243.

[8] Morgan and P. W. A. Tovellt: The structure of the gill of the trout, Salmo gairdneri (Richardson). Z. Zellforsch. Mikroskop. Anat. 142 (1973), 147-162.

[9] Ortiz, J., De Canales, M. and Sarasquete, C. (2003). Histopathological changes induced by lindane $(\gamma-$ $\mathrm{HCH})$ in various organs of fishes. Sci. Mar., 67 (1):53-61.

[10] Perry, S.E. and Laurent, P. 1993. Environmental effects on fish gill structure and function. In: Fish ecophysiology (Ranklin, J.C. and Jenseu, F.B. Eds.). Chapman and Hall. London. 231-264.

[11] Srivastava, Rajesh K., Kamlesh K.Yadav and Sunil P .Trivedi. 2008. Devicyprin induced gonadal impairment in a fresh water food fish Channa punctatus (Bloch).j.Environ.Biol. 29,187-191.

[12]T. Senapati, A. K. Mukerjee and A. R. Ghosh Observations on the effect of glyphosate based herbicide on ultra structure (SEM) and enzymatic activity in different regions of alimentary canal and gill of Channa punctatus (Bloch) Journal of Crop and Weed, 5(1): 233-242 (2009).

[13] Yogitha Devi and Abha Mishra 2013 Histopathological Alterations in Gill and Liver Anatomy of Fresh Water, Air Breathing Fish Channa Punctatus after Pesticide Hilban (Chlorpyrifos) Treatment. Adv. Biores., Vol4 (2) June 2013: 57- 62.

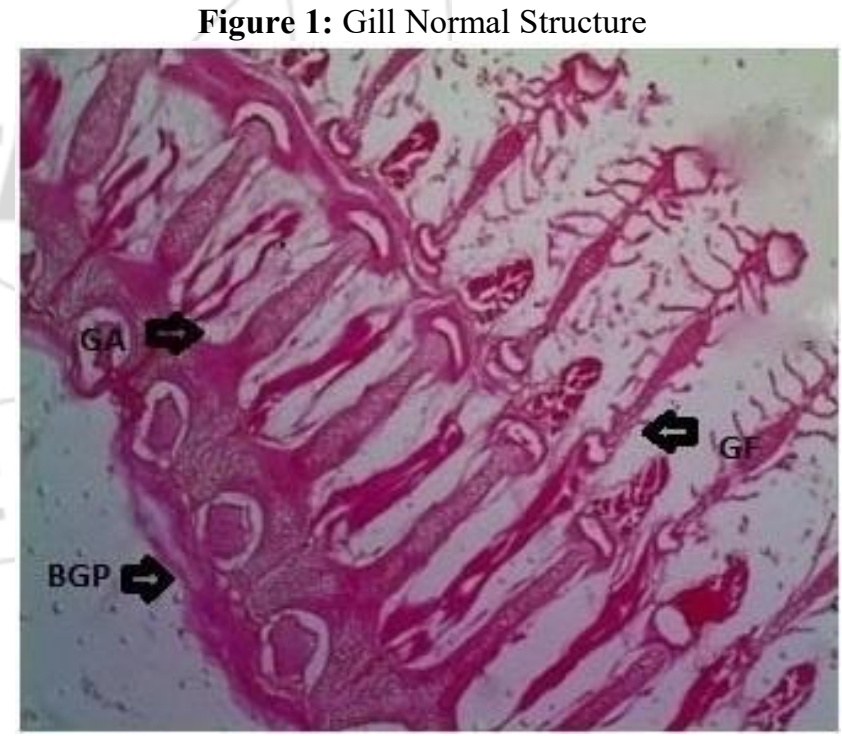

GA-Gill Arch, GF-Gill Filament, BGP-Basal Gill Pouch. (100X) 


\section{International Journal of Science and Research (IJSR) \\ ISSN (Online): 2319-7064 \\ Index Copernicus Value (2013): 6.14 | Impact Factor (2014): 5.611}

Figure 2: Gill Treated with Bordeaux mixture

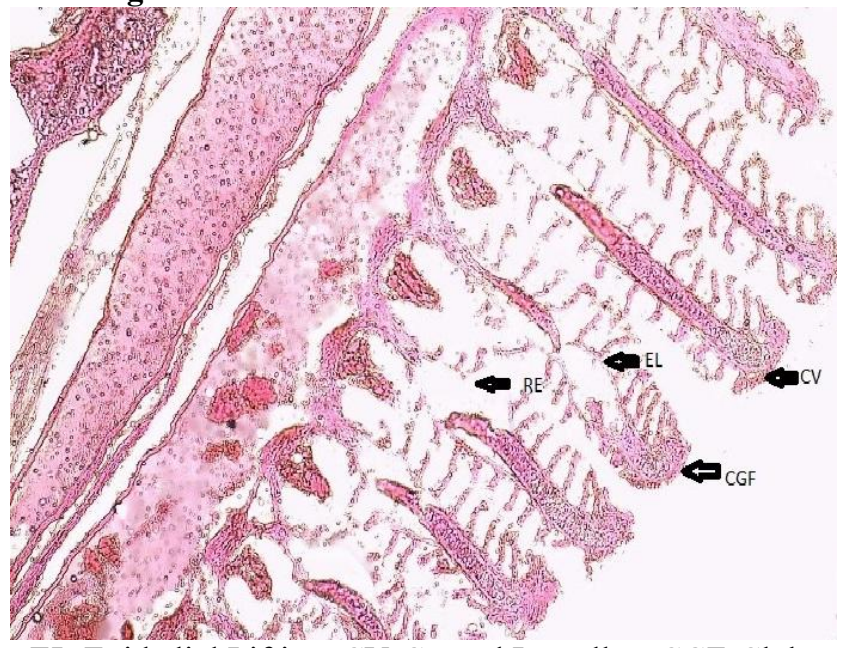

EL-Epithelial Lifting, CV-Curved Lamellae, CGF-Club shaped Gill Filaments, EL-Epithelial Lifting, RE-Ruptured Gill Epithelium.(100X)

Figure 3: Tip of a Gill Filament Treated with Bordeaux mixture

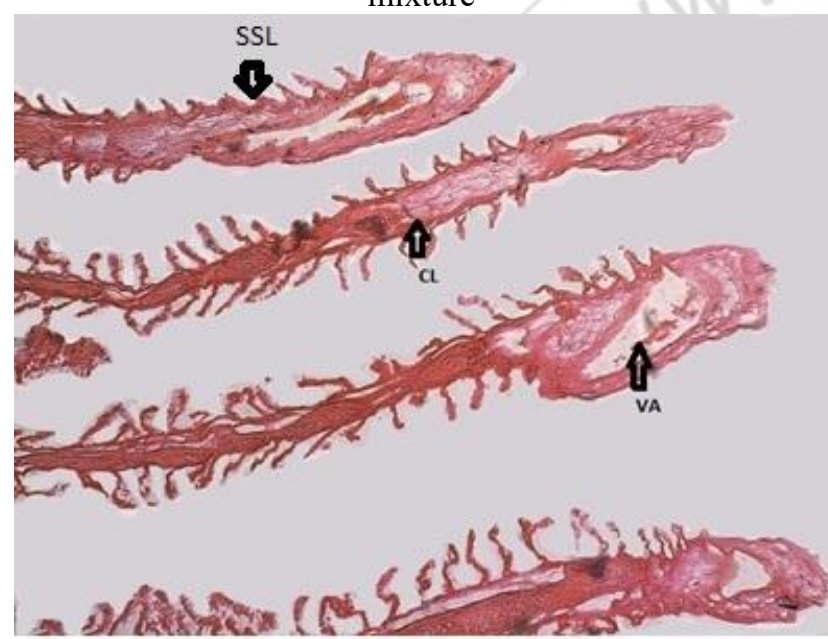

SSL-Spiked Secondary Gill Lamellae, CL-Capillary Lumen Space Increased, VA-Vacuolization at the tip of lamellae.(100X)
Figure 6: Gill Treated with Bordeaux mixture

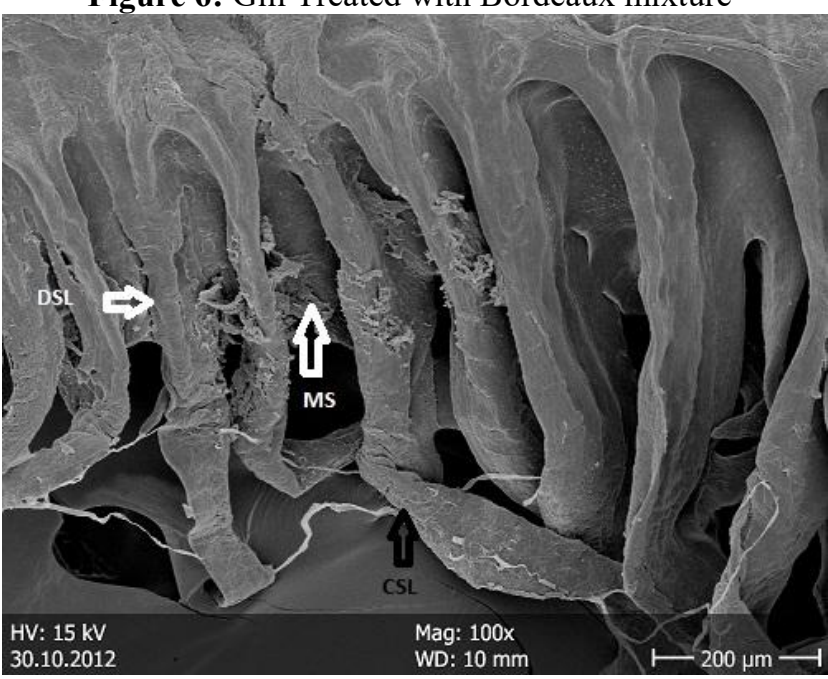

DSL-Degenerated Secondary Gill Lamellae, MS-Mucus Secretion, CSL-Curved Secondary gill Lamellae.

Figure 7: Gill Treated with Bordeaux mixture.

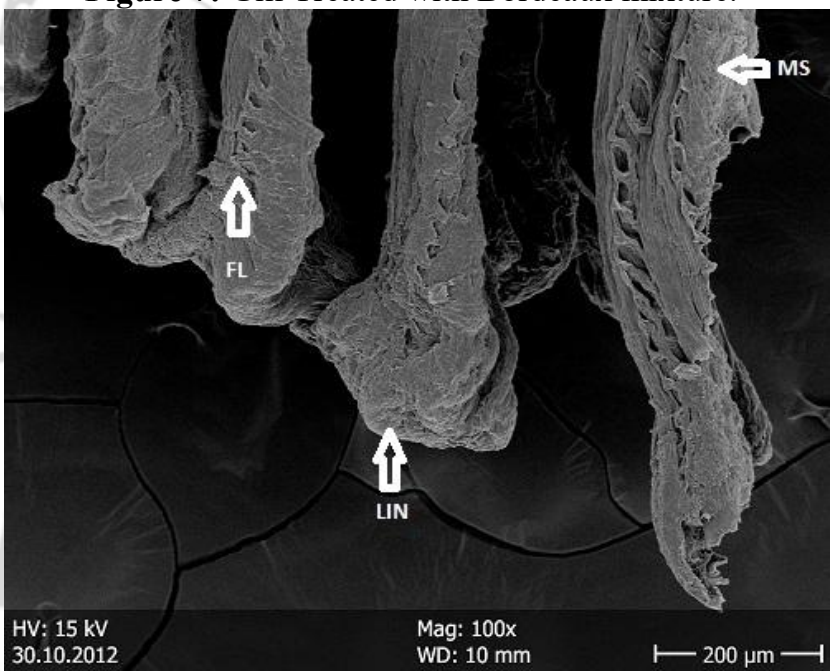

MS-Mucus Secretion, FL-Fusion of Lamellae, LINLamellar Inflammation

Figure 5: SEM Analysis of Gill Normal

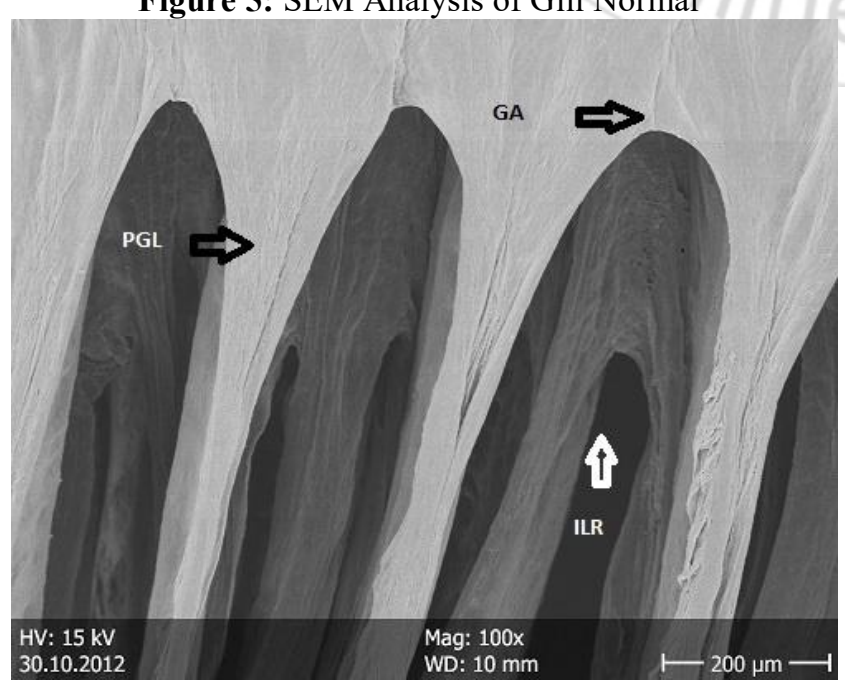

GA-Gill Arch, PGL-Primary Gill Lamellae, ILR-Inter Lamellar Region. 